\title{
Erratum to: The central vein access port and catheter in outpatient chemotherapy for colorectal cancer: a retrospective study of 101 patients
}

\author{
Hiroshi Sawayama $\cdot$ Naoko Hayashi • \\ Masayuki Watanabe $\cdot$ Hiroshi Takamori $\cdot$ \\ Toru Beppu $\cdot$ Hideo Baba
}

Published online: 14 March 2013

(C) Springer Japan 2013

Erratum to: Surg Today (2012) 42:29-34

DOI 10.1007/s00595-011-0016-5

An error appeared in the above-cited article.

In the Abstract, in the "Results" subsection (page 29, line 10), and in the Results section (page 30, line 5) it was incorrectly reported that an overall total of 1035 chemotherapeutic courses were administered. The total number of courses was actually 1020. It was confirmed that this mistake did not influence any other results in this article. The authors sincerely apologize for the error.

The online version of the original article can be found under doi:10.1007/s00595-011-0016-5.

H. Sawayama - N. Hayashi - M. Watanabe - H. Takamori ·

T. Beppu $\cdot$ H. Baba $(\bowtie)$

Department of Gastroenterological Surgery,

Graduate School of Medical Sciences,

Kumamoto University, 1-1-1 Honjo,

Kumamoto 860-8556, Japan

e-mail: hdobaba@kumamoto-u.ac.jp 